Pak. j. sci. ind. res. Ser. B: Biol. sci. 2019 62B(2) 97-100

\title{
Antibacterial Activity of Pakistani Honey
}

\author{
Taif Shah ${ }^{a *}$, Niyaz Ali ${ }^{\mathrm{a}}$, Zahir Shah ${ }^{\mathrm{b}}$ and Azam Hayat \\ ${ }^{a}$ Department of Microbiology, Hazara University Garden Campus, Mansehra-21300, \\ Khyber Pakhtunkhwa, Pakistan \\ ${ }^{b}$ Department of Animal Health, Faculty of Animal Husbandry \& Veterinary Sciences, \\ The University of Agriculture, Peshawar-25120, Pakistan \\ ${ }^{c}$ Department of Microbiology, Abbottabad University of Science and Technology, Abbottabad, Pakistan
}

(received February 16, 2017; revised August 25, 2017; accepted November 30, 2017)

\begin{abstract}
The current study was conducted to determine the antibacterial activity of 50 crude and processed honey samples produced by Apis mellifera and stingless bee. All the honey samples were collected from different places of Districts Dir, Swat and Oghi of Khyber Pakhtunkhwa Province, Pakistan and were tested against the six ATCC bacterial species including E. coli ATCC number 25922, Pseudomonas aeruginosa ATCC number 27853, Staphylococcus aureus ATCC number 6538, Enterococcus faecalis ATCC number 19433, Salmonella typhi ATCC number 19943 and Klebsiella pneumoniae ATCC number 27736. The honey samples showed variable zones of inhibition by using Agar well plate technique. E. coli showed 17-23 mm, S. typhi 31-37 mm, E. faecalis $28 \mathrm{~mm}$, P. aeruginosa 14-15 mm, K. pneumoniae 20-24 mm and Staph. aureus 19-25 mm. Most of the honey samples used in this study showed broad spectrum antibacterial activity.
\end{abstract}

Keywords: antibacterial activity, honey, zones of inhibition, agar well diffusion method

\section{Introduction}

Honey produced by honey bees (Apis mellifera) is one of the oldest traditional medicines used against several human diseases (Manisha et al., 2011). Honey inhibits the growth of many pathogenic bacteria including, Escherichia coli (E. coli), Staphylococcus aureus (Staph. aureus) and Salmonella typhi (S. typhi) (Zumla and Lulat, 1989). It has been reported that honey has a bacteriostatic and bactericidal effect against various species of gram positive and gram negative bacteria (Nzeako, 2000; Molan and Betts, 2000). The antibacterial activity of honey may be due to the presence of hydrogen peroxide (Molan, 1992).

Antibiotics are very important agents in reducing global burden of bacterial infections. However, the effectiveness of drugs is reduced due to the development of drugs resistant bacteria (WHO, 1999), which is an increasing problem in the world (Shears, 2000).

Globally, due to lack of access to health care, infectious diseases account for $25 \%$ of mortality (Mandal et al., 2011). Currently, Herbal and modern scientific medicine has gained importance globally (WHO, 2000). The purpose of this research was to evaluate the antibacterial

*Author for correspondence; E-mail: taifshah@yahoo.com activity of Pakistani honey produced by Apis mellifera against various pathogenic bacteria.

\section{Materials and Methods}

A cross-sectional study was performed to evaluate the antibacterial activity of Pakistani honey against different bacterial species. Locally manufactured honeys were collected from different beekeepers and super markets of Districts Dir, Swat and Oghi, Pakistan and brought to the Microbiology Laboratory, Hazara University, Mansehra, Pakistan for antibacterial analysis. Out of total 50 honey samples collected, each sample was filtered through a sterile mesh to remove debris followed by streaking on blood agar culture media plate and was then incubated overnight to check for microbial purity.

Bacterial isolates were procured from the American Type Culture Collection (ATCC), Veterinary Research Institute (VRI) Abbottabad, Pakistan. A total of six bacterial strains were used including, E. coli with ATCC number 25922, Pseudomonas aeruginosa with ATCC number 27853, Staphylococcus aureus with ATCC number 6538, Enterococcus faecalis with ATCC number 19433, Salmonella typhi with ATCC number 19943 and Klebsiella pneumoniae with ATCC number 27736. The bacterial isolates were confirmed through standard microbiological techniques and drug susceptibility tests 
following standard agar disc diffusion method. For further use, bacterial isolates were stored in the laboratory on nutrient agar slopes at $4{ }^{\circ} \mathrm{C}$.

Morphologically identical bacterial colonies from overnight growth culture tubes were picked up with sterilized wire loop and were then suspended in $3 \mathrm{~mL}$ of nutrient broth following incubation for $3 \mathrm{~h}$ at $37^{\circ} \mathrm{C}$. Bacterial dilution was prepared with normal saline to a turbidity of $0.5 \mathrm{McF}$ arland standards (108 colony forming unit $/ \mathrm{mL}$ ). Agar well diffusion technique was used for checking antibacterial activity of honey against the recommended bacterial strains. A wire loop full of prepared bacterial suspensions $(1 \times 104 \mathrm{cfu} / \mathrm{mL})$ were applied to the center of a sterile Mueller Hinton culture media plate and spread evenly throughout the plates by using a sterile dry cotton wool.

Different concentrations, $10,20,50$ and $75 \% \mathrm{v} / \mathrm{v}$ of each honey sample were made in sterile distilled water. These were obtained by dissolving $0.1,0.2,0.5$ and $0.75 \mathrm{~mL}$ of each honey into desired volumes of water. Similarly, one hole was drilled at the center of culture media plate and $50 \mu \mathrm{L}$ of each honey dilution. Negative control well only contained $50 \mu \mathrm{L}$ of sterile distilled water and all the culture plates were incubated at $37^{\circ} \mathrm{C}$ for $24 \mathrm{~h}$. The diameters of inhibitory zones were measured in millimeter. This experiment was repeated three times to ensure reproducibility and to be able to calculate an average value for each honey.

\section{Results and Discussion}

In the present research work, all the honey samples were found pure following streaked for purity. The antibacterial activity of honey samples were checked against E. coli, S. typhi, E. faecalis, $P$ aeruginosa, $K$. pneumoniae and Staph. aureus (Fig.1). Following Agar well plate technique, the highest degree zone of inhibition was observed against E. coli $(17-23 \mathrm{~mm})$ as shown in Fig.1. Similarly, the zone of inhibition of each honey sample against $S$. typhi $(31-37 \mathrm{~mm})$, E. faecalis $(28 \mathrm{~mm})$, K. pneumoniae (18-21mm), Staph. aureus (19-25mm) and $P$. aeruginosa $(14-15 \mathrm{~mm})$ was also reported as shown in Table 1.

Antibacterial activity of honey has been reported since long time especially for wound healing which may be due to its complex composition and ability to generate hydrogen peroxide by the bee-derived enzyme glucose oxidase (Vallianou et al., 2014; Lu et al., 2014).
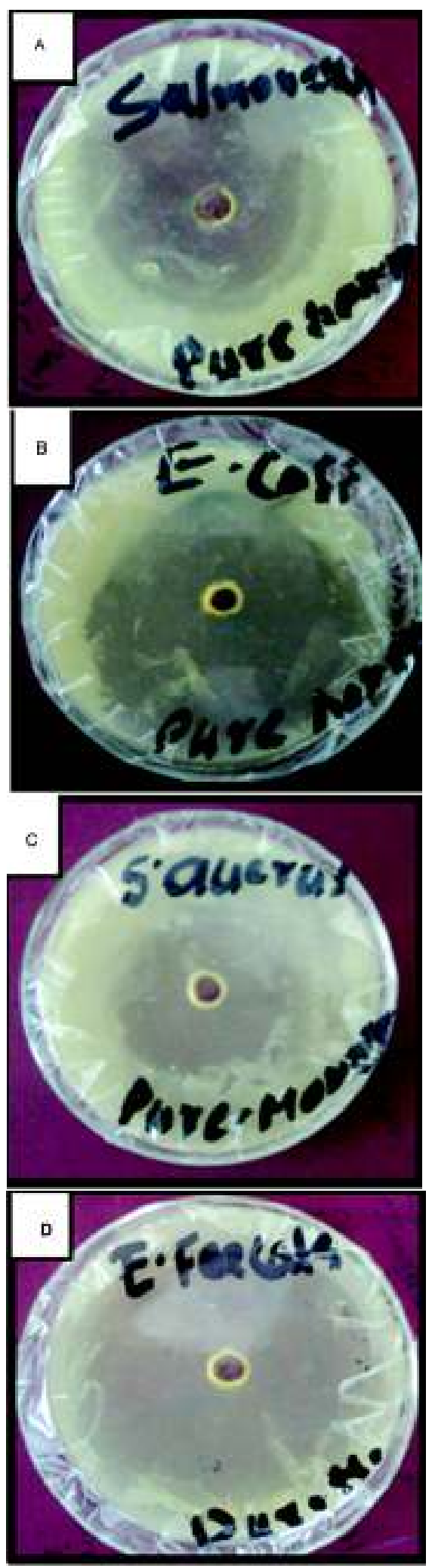

Fig. 1. Visible zone of inhibition of honey samples against (A) S. typhi, (B) E. coli, (C) Staph. aureus and (D) E. faecalis. 
Table 1. Zone of inhibition of honey against E. coli, S. typhi, E. faecalis, K. pneumoniae, Staph. aureus and P. aeruginosa.

\begin{tabular}{lllllll}
\hline \hline Location & \multicolumn{5}{c}{ Zone of inhibition of honey (mm) } \\
\cline { 2 - 7 } & E. coli & S. typhi & E. faecalis & K. pneumoniae & Staph. aureus & P. aeruginosa \\
\hline Dir Lower & 22.6 & 31.4 & 28.3 & 20.9 & 24.6 & 15.4 \\
Swat & 17.6 & 35.2 & 28.7 & 22.9 & 19.8 & 14.7 \\
Oghi & 23.6 & 37.3 & 28.8 & 24.4 & 25.2 & 15.9 \\
(Mansehra) & & & & & \\
\hline \hline
\end{tabular}

Hegazi (2011), reported the antibacterial activity of different honey (Acacia honey, Citrus honey, Clover honey, Coriander honey, Cotton honey, Palm honey, Sesame honey and Saudi Seder honey) against $K$. pneumoniae, $P$. aeruginosa and E. coli. Honey has antibacterial activity against Staph. aureus, E. faecalis, E. coli, P. aeruginosa, K. pneumoniae and S. typhi (Mohapatra et al., 2011). The bacteriostatic or bactericidal activity depends on the type of honey samples (Lu et al., 2014). It is reported that antibacterial effect exhibited by honey was related to the levels of hydrogen peroxide present in the honey (Irish et al., 2011). Researchers at the Waikato Honey Research Unit (2012) in New Zealand attributed the antibacterial activity of honey to its acidic PH (3 to 4.5) as most bacteria can best grow at neutral PH (7-7.4). All the honey brands used in this study were effective against E. coli, E. faecalis, P. aeruginosa, S. typhi, K. pneumoniae and Staph. auerus which concur with several similar reports (Melissa et al., 2004; Taormina et al., 2001).

Present results showed that Swat honey was effective against E. coli (17-23mm), S. typhi (31-37mm), and Staph. aureus (24-29mm) zone of inhibition observed for each bacterial strain. It was also observed the same results when our research data was compared to the previous reports in which $E$. coli showed $15-20 \mathrm{~mm}, S$. typhi $30-50 \mathrm{~mm}$ and $S$. aureus showed $17-20 \mathrm{~mm}$ zones of inhibition (Dilnawaz et al., 1995). In another similar reports, E. coli showed $17-23 \mathrm{~mm}$, S. typhi $30-35 \mathrm{~mm}$ zone and Staph. aureus showed 19-25mm zone of inhibition (Nuriza-Tumin et al., 2005). While our results show 17-23mm for E. coli, 24-29mm for S. typhi, 19$25 \mathrm{~mm}$ for Staph. aureus. Similarly, antibacterial activity of honey against E. coli, Staph. aureus showed 8-45 and $12-45 \mathrm{~mm}$ zones of inhibition, respectively. Honey has also antibacterial activity against Shigella species (Omoya and Akharaiyi, 2010). Antibacterial activity of honey against E. coli, Staph. aureus, E. faecalis, $P$. aeruginosa, K. pneumoniae and $S$. typhi have been also reported in many previous research studies (Molan and Betts, 2000).

\section{Conclusion}

Honey is widely researched and has well-known antibacterial activity. It is very effective against several gram negative and gram positive bacteria. This study demonstrates that honey has antibacterial activity. Therefore, it is necessary to study healing property of honey in-vivo as well as its mechanism of action.

\section{Acknowledgement}

We are grateful to the Department of Microbiology, Hazara University Mansehra, Pakistan, for facilitating this study.

Conflict of Interest. The authors declare no conflict of interest

\section{References}

Hegazi, A.G. 2011. Antimicrobial activity of different Egyptian honey as comparison of Saudi Arabia honey. Journal of Microbiology, 6: 488-495.

Irish, J., Blair, S., Carter, D.A. 2011. The antibacterial activity of honey derived from Australian flora. PLoS One, 6: e18229.

Lu, J., Turnbull, L., Burke, C.M., Liu, M., Carter, D.A., Schlothauer, R.C., Whitchurch, C.B., Harry, E.J. 2014. Manuka-type honeys can eradicate biofilms produced by Staphylococcus aureus strains with different biofilm-forming abilities. Peer Journal, 2: e326. doi: 10.7717.

Mandal, M.D., Mandal, S. 2011. Honey: its medicinal property and antibacterial activity. Asian Pacific Journal of Tropical. Biomedicine, 1: 154-160. 
Manisha, D.M., Shyamapada, M. 2011. Honey: its medicinal property and antibacterial activity. Asian Pacific Journal of Tropical Biomedicine, 1: 154160.

Melissa, A.M., Olga, I.P.Z., Randy, W.W. 2004. Growth inhibition of food borne pathogens and food spoilage organisms by select raw honeys. International Journal of Food Microbiology, 97: 1-8.

Mohapatra, D.P., Thakur, V., Brar, S.K. 2011. Antibacterial efficacy of raw and processed honey. Biotechnology Research International, doi: 10.4061/ 2011/917505.

Molan, P.C., Betts, J. 2000. Using honey dressings: The practical considerations. Nursing Times, 96: 36-37.

Molan, P.C. 1992. The antibacterial activity of honey: 1. the nature of the antibacterial activity. Bee World, 73: 5-28.

Nzeako, H. 2000. Antimicrobial potential of honey. Medical Science, 2: 75-79.

Shears, P. 2000. Antimicrobial resistance in the tropics.
Tropical Doctor, 30: 114-116.

Taormina, P.J., Niemira, B.A., Bauchat, L.R. 2001. Inhibitory activity of honey against foodborne pathogens as influenced by the presence of hydrogen peroxide and level of anti-oxidant power. International Journal of Food Microbiology, 69: 217-225.

Vallianou, N.G., Gounari, P., Skourtis, A., Panagos, J., Kazazis, C. 2014. Honey and its anti-inflammatory, anti-bacterial and antioxidant properties. General Medicine, 2: 132.

WHO, 2000. Herbal Medicine In: Drug information vol. 14, pp. 237-243, World Health Organization Geneva, Switzerland.

WHO, 1999. Drug Information. World Health Organization, vol. 13, pp. 230-233. Geneva, Switzerland.

Zumla, A., Lulat, A. 1989. Honey a remedy rediscovered. Journal of the Royal Society of Medicine, 82: 384385 . 